\title{
Occipital emissary foramina in human skulls: review of literature and proposal of a classification scheme of the occipital venous anastomoses in the posterior cranial fossa
}

\author{
Lazar Jelev (iD), Lina Malinova (D) \\ Department of Anatomy, Histology and Embryology, Medical University of Sofia, Sofia, Bulgaria
}

\begin{abstract}
Objectives: The present study aims to explain the interesting discrepancy between the occipital emissary foramina and the respective emissary veins in the literature. Majority of the studies report that the foramina have a low and variable frequency, but the emissary veins are reported to be disproportionately present in quite large number of patients in some diagnostic imaging studies.
\end{abstract}

Methods: Seventy-five adult skulls were examined for the presence of occipital foramina.

Results: A complete occipital emissary foramen was found only in one skull (1.33\%), but a number of other skulls also showed some foramina on the external and internal surfaces of squamous part of the occipital bone.

Conclusion: It can be concluded that foramina of another vein which is related to the squamous part of occipital bone, the occipital diploic vein, might be the main reason for the discrepancies present in the literature. The suggested classification scheme of venous anastomoses in the posterior cranial fossa can explain the variable bony foramina observed in skull series.

Keywords: human; occipital emissary foramen; occipital emissary vein; skull; vein anastomoses

Anatomy 2020;14(1):11-15 @2020 Turkish Society of Anatomy and Clinical Anatomy (TSACA)

\section{Introduction}

In the textbooks of human anatomy there is an interesting discrepancy between one of the skull foramina and the respective structures contained within. According to Terminologia Anatomica, ${ }^{[1]}$ the occipital emissary vein $(\mathrm{OEV})$ is one of the four emissary veins, but the respective occipital emissary foramen (OEF) is not even mentioned in the textbook descriptions of occipital bone and posterior cranial fossa. ${ }^{[2-4]}$ Reviewing the pertinent literature, it seems that this bony foramen in skull series shows low and quite variable frequency ${ }^{[5-13]}$ Additionally, it is demonstrated with much higher incidence in diagnostic imaging studies ${ }^{[1,15]}$ With the present study, based on examination of human skulls, and after reviewing the literature, we aimed to explain the discrepancies between the reported incidence of the OEF and OEV, which might help radiologists in diagnosing specific pathologies in the dural sinus system $^{[14,15]}$ and also neurosurgeons performing approaches to the posterior cranial fossa. ${ }^{[16]}$

\section{Materials and Methods}

A total of 75 adult skulls from the bony collection available at the Department of Anatomy, Histology and Embryology of the Medical University of Sofia, Bulgaria were examined. We used, when necessary, the wire probe method for estimation of size of bony foramina as described by Boyd.$^{[5]}$ Most of the skulls belonged to elderly individuals (60-80-year-old). Forty four belonged to females and 31 to males. For this study, all the foramina on both inner and outer surfaces of squamous part of occipital bone and especially around the midline were recorded and analyzed. A descriptive statistical approach was used to represent the data in terms of frequency (\%). 


\section{Results}

A complete OEF was found only in 1 skull belonging to a female, that makes the incidence of OEF as $2.27 \%$ for female skulls and $1.33 \%$ for the total skulls in our series. The foramen (Figures 1a and $\mathbf{b}$ ) allowed a wire probe of $1.5 \mathrm{~mm}$ to pass completely through. Externally, its opening was located just on the left side of the external occipital crest at a distance of $9 \mathrm{~mm}$ from the border of foramen magnum. The inner aperture was in the posterior cranial fossa, slightly to the left of the midline and within the splitting formed by the lower end of the internal occipital crest. In a number of other skulls, the description of occipital foramina was more complicated (Figures $2 \mathrm{a}-\mathbf{d}$ ). In some cases, there were only visible openings from outside (6 skulls, $8 \%$ ) or inside (12 skulls, $16 \%$ ) of the squamous part of occipital bone, or both inner and outer openings were presented (10 skulls, $13.3 \%$ ), but not connected and probably belonging to different vessels but the OEV. Passing through all of these aforementioned openings was not possible even with the thinnest wire probe. In most of the cases, the external occipital foramina (EOF) were grouped around the external occipital crest below the level of inferior nuchal line (Figure 2a). They were rarely found around the external occipital protuberance and even once found much higher in the midline of the upper part of the squamous part of the occipital bone (Figure $2 \mathbf{b}$ ). The internal occipital foramina (IOF) (Figures $2 \mathbf{c}$ and $\mathbf{d}$ ) were identified most commonly on the internal occipital protuberance or on the triangular extension of the internal occipital crest. In 42 of the skulls of our series (15 male and 27 female skulls) no foramina were identified on either the inner or outer surface of the squamous part of occipital bone. Some bony lytic defects were observed in 4 of the skulls (5.33\%). The data collected from our skull series are summarized in Table $\mathbf{1}$.

\section{Discussion}

Some of the skull bones contain small perforating foramina especially for the emissary veins, which connect the dural venous sinuses with the extracranial veins. ${ }^{[2-4]}$ Four main emissary veins are usually described in Terminologia Anatomica, ${ }^{[1]}$ including parietal emissary, mastoid emissary, condylar emissary and occipital emissary veins.
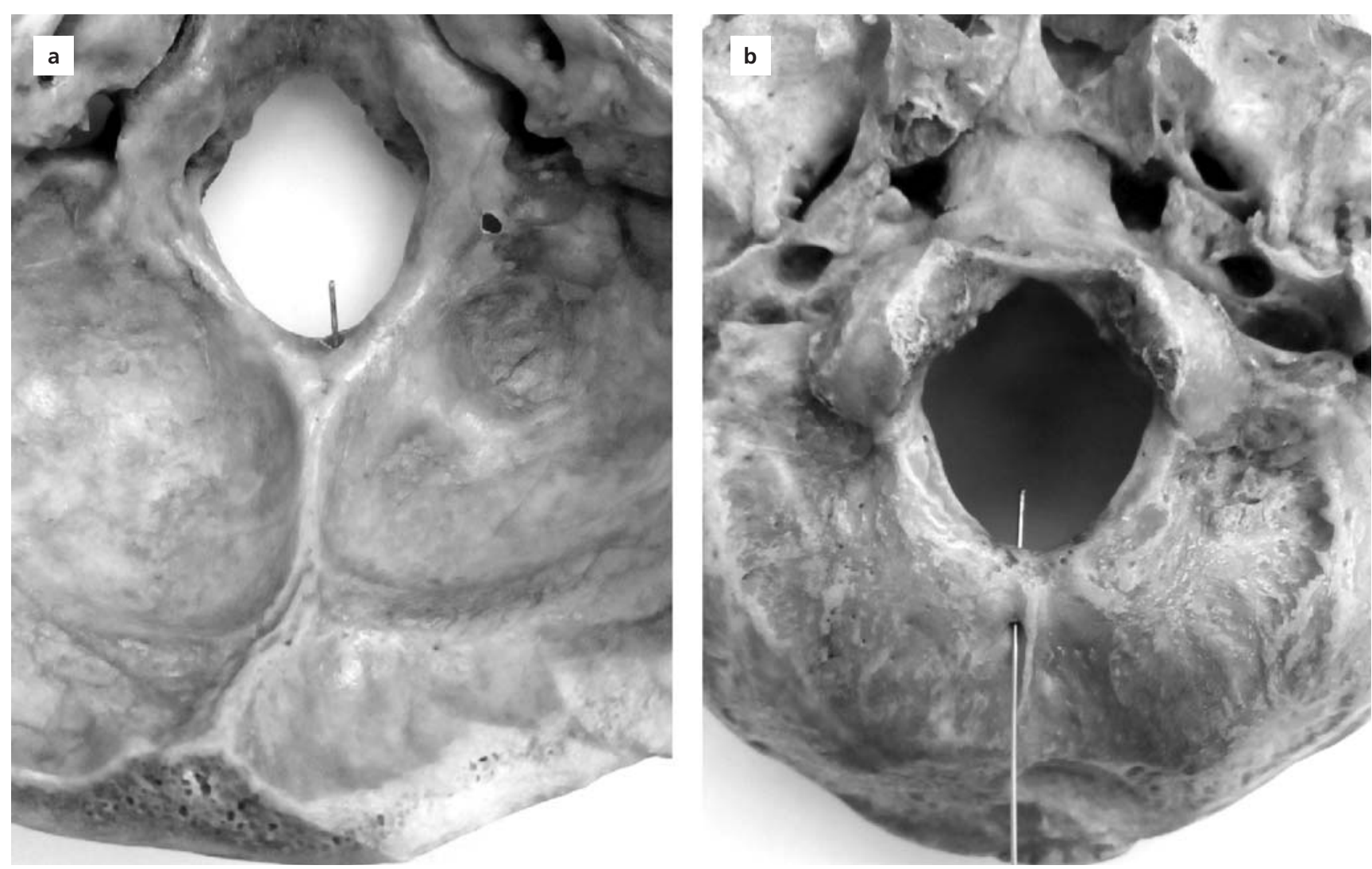

Figure 1. Photographs of a complete OEF with the wire probe showing the inner (a) and outer (b) openings. OEF: occipital emissary foramen. 
Bearing in mind the morphology of the common (despite not always present) parietal and mastoid foramina and condylar emissary canal, the "emissary foramen" (or canal) should be a complete passage through the skull bone that contains a short anastomosing (emissary) vein between a dural venous sinus and an extracranial vein.

Our examinations revealed that the OEF showed a low incidence and had specific morphology. We observed that $\mathrm{OEF}$ is usually a single direct bony passage around the midline and close to the border of foramen magnum. One of the studies describing the lowest frequency of OEF also in a series of Bulgarian skulls was published by Kadanoff and Mutafov. ${ }^{[6]}$ In this extensive study on 5000 skulls, the foramen was found only twice $(0.04 \%)$ and it was called "foramen occipitale accessorium". In some other studies, the incidence of OEF was reported as $0.46 \%(1 / 214),{ }^{[7]}$ $1.6 \%(24 / 1500),{ }^{[5]} 2 \%(7 / 338),{ }^{[8]} 2.6 \%(8 / 300) .{ }^{[9]}$ There are also papers describing higher incidence of complete OEF in skull series $-9.5 \%(21 / 221),{ }^{[13]} 14 \%(21 / 150),{ }^{[10]}$ and $14.1 \%(11 / 78){ }^{[12]}$ If we consider higher incidence of this foramen in Indian and Bangladeshi populations, ${ }^{[10,12,13]}$ then a very low frequency $(0.46 \%)$ in the Indian population was also reported by Sharma et al. ${ }^{[7]}$

In a study of 100 dry skulls and 100 dissected cadaveric heads, Louis et al. ${ }^{[11]}$ reported OEF in $11 \%(22 / 200)$, as the number of emissary foramina varied between one and three. However,the study revealed some limitations. The authors didn't demonstrate a complete emissary foramen by passing of a wire probe through the occipital bone, as reported in other skull studies..$^{[8,912,13]}$ Probably, in this study, the percentage of complete emissary foramina was increased by counting all identifiable foramina on the external surface of the occipital bone (in dry skulls) and the foramina through which a vein passes to join the occipital vein (in cadaveric heads).

The location and the route of these bony foramina were explained in some earlier studies. In a corrosion cast study describing the craniocervical venous system and the
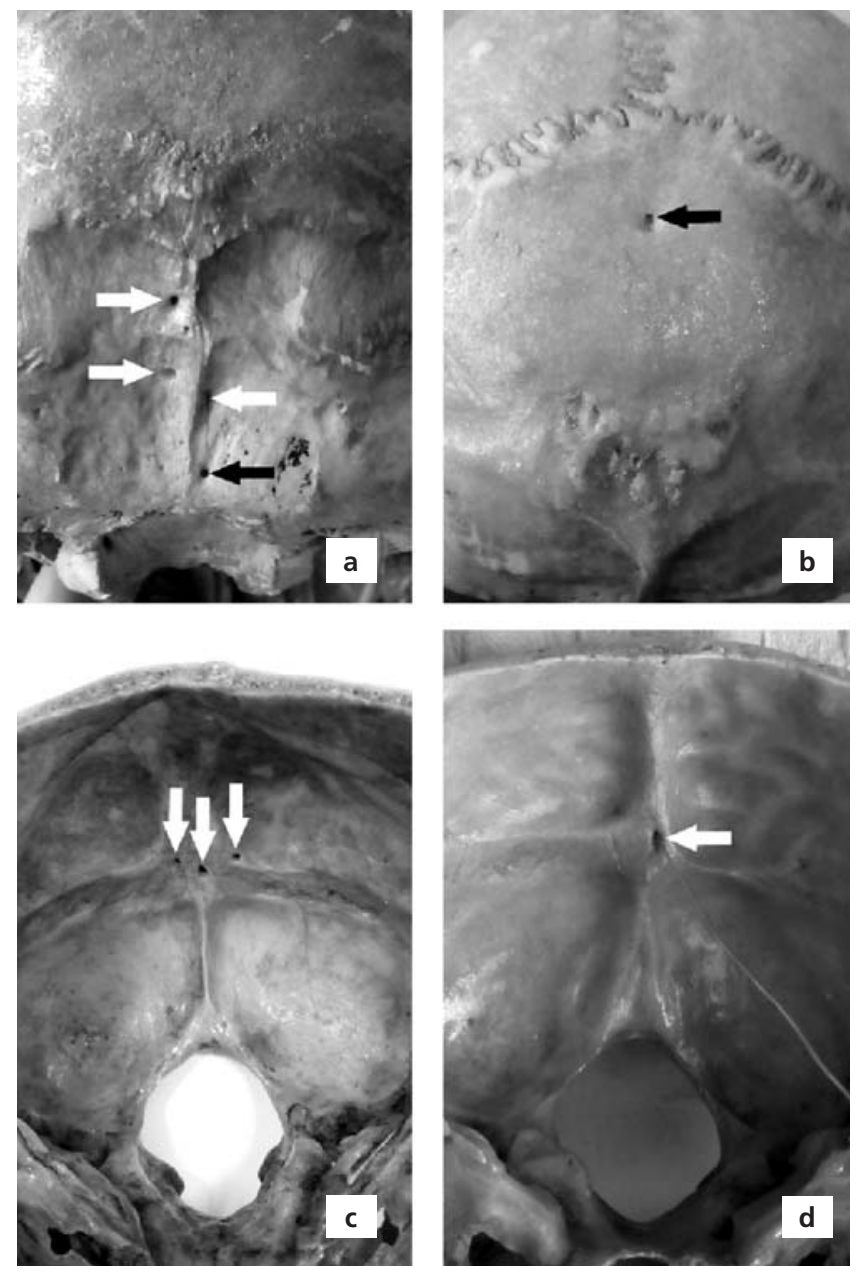

Figure 2. Photographs of the external $(\mathbf{a}, \mathbf{b})$ and internal $(\mathbf{c}, \mathbf{d})$ occipital foramina. (a) The foramina were grouped around the external occipital crest; (b) an external foramen in the midline in the upper squamous part of occipital bone is shown; (c) three foramina on the internal occipital protuberance are demonstrated; (d) single internal foramen.

venous anastomoses in the posterior cranial fossa, $\mathrm{OEV}$ was found in $8.3 \%{ }^{[17]}$ It was observed that the OEV was connecting confluence of sinuses (torcula) with an occipi-

Table 1

Data on 75 human skulls.

\begin{tabular}{|c|c|c|c|c|c|c|}
\hline \multirow[b]{2}{*}{ Bony findings } & \multicolumn{2}{|c|}{ Male skulls } & \multicolumn{2}{|c|}{ Female skulls } & \multicolumn{2}{|c|}{ Total skulls } \\
\hline & Number & Percentage & Number & Percentage & Number & Percentage \\
\hline Complete OEF & 0 & 0 & 1 & $2.27 \%$ & 1 & $1.33 \%$ \\
\hline EOF & 3 & $9.68 \%$ & 3 & $6.82 \%$ & 6 & $8.00 \%$ \\
\hline IOF & 5 & $16.13 \%$ & 7 & $15.91 \%$ & 12 & $16.00 \%$ \\
\hline $\mathrm{EOF}+\mathrm{IOF}$ & 6 & $19.35 \%$ & 4 & $9.09 \%$ & 10 & $13.33 \%$ \\
\hline Bony lytic defects & 2 & $6.45 \%$ & 2 & $4.55 \%$ & 4 & $5.33 \%$ \\
\hline None & 15 & $48.39 \%$ & 27 & $61.36 \%$ & 42 & $56.00 \%$ \\
\hline
\end{tabular}

EOF: external occipital foramen; IOF: internal occipital foramen; OEF: occipital emissary foramen. 
tal vein, but the precise passage through the squamous part of occipital bone was not described because all the soft tissues and bones were already dissolved.

In a MRI study on axial images, Cakmak et al. ${ }^{[14]}$ reported the $\mathrm{OEV}$ in $28 \%$ of the cases examined. In another imaging study on subtracted CT venography and contrast enhanced MRI, Hedjoudje et al ${ }^{[15]}$ examined the OEV and reported its presence in $65.2 \%$ of the patients with increased pressure in the transverse sinus system versus $31.5 \%$ of the patients without pressure signs. Interestingly, however, the whole study is based on an identifiable occipital anastomosing vein connecting the confluence of sinuses or distal part of the superior sagittal sinus with the occipital vein. This anastomosing vein was descending intraosseously for several centimeters within the squamous part of occipital bone. The exit point of the OEV was described between the external occipital protuberance and the foramen magnum, as multiple foramina were also found in $3.2 \%$.

The development of the OEV in human embryos was mentioned in a study by Okudera et al., ${ }^{[18]}$ and it was noted that this vein appeared occasionally from the confluence of sinuses and penetrating the occipital bone as it passes below the external occipital protuberance to join the suboccipital veins.

One of the main reasons for the discrepancies in the reported incidence of the OEF and OEV might be simply the descriptions of some bony openings for another venous systems but the emissary vein system. Basically, the
OEV should connect a dural venous sinus with an extracranial vein, however, another vein is also drained here, and that is the occipital diploic vein. ${ }^{[2-4]}$ In anatomy textbooks, the occipital diploic vein is described as the largest one that drains internally to the transverse sinus or confluence of sinuses or externally to the occipital vein. ${ }^{[2-4]}$ Bearing in mind the great variability of the veins in the human body and lack of valves in the emissary veins, ${ }^{[2,3]}$ we can speculate that actually we have three venous systems anastomosing here, including dural venous sinuses, occipital diploic vein and the extracranial occipital vein, that makes possible several variant venous patterns to exist among individuals (Figures 3a-d). Most importantly, the variant venous patterns will be reflecting the variable patterns of the occipital foramina on the surface of the occipital bone and will explain the direct (through the emissary vein) and indirect (through the diploic vein) connections between the dural venous sinuses and the occipital vein.

\section{Conclusion}

In conclusion, we can identify some kind of misunderstanding between the anatomical and clinical descriptions of the OEF and OEV. From anatomical point of view, if we refer to the proposed classification system (Figure 3d), an OEV should rarely found having a short course andmaking a direct anastomosis through a complete OEF, which connects a dural sinus with an extracranial vein. In the imaging studies, however, even a longer intraosseous anastomosis is called as $\mathrm{OEV},^{[15]}$ although it should be
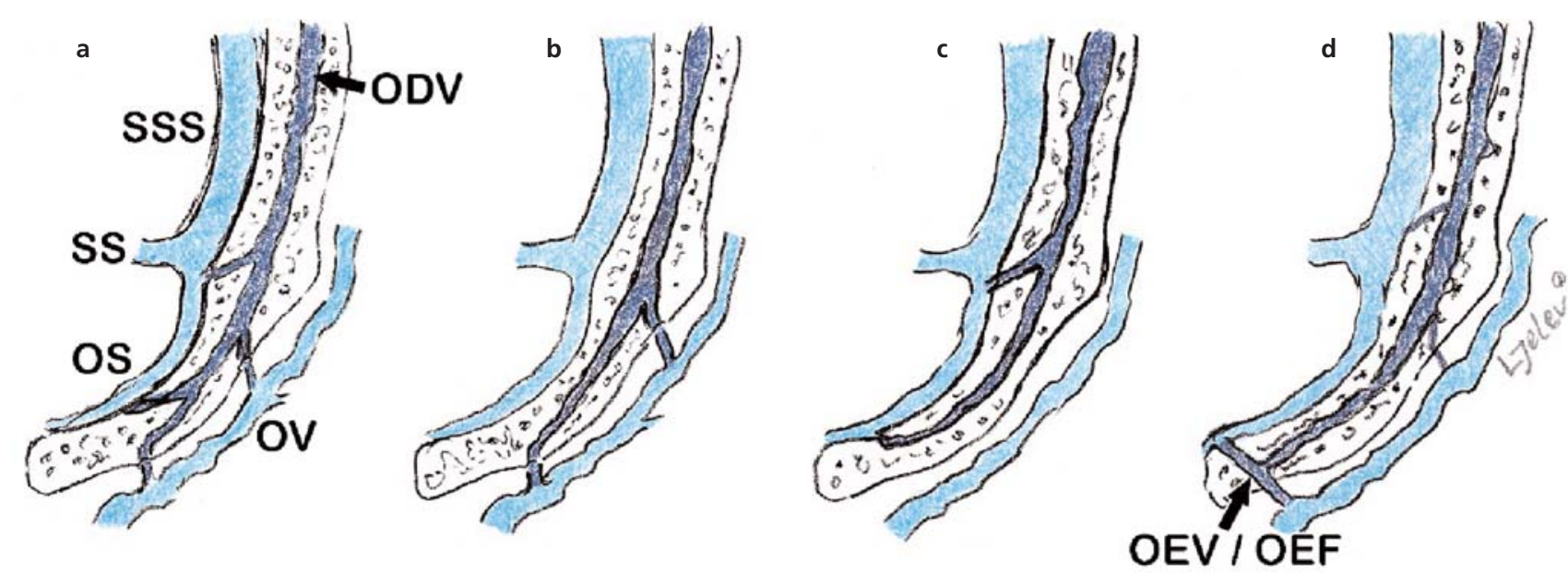

Figure 3. Classification scheme of the variable anastomoses between the dural venous sinuses, occipital diploic vein and extracranial occipital vein In (a) the diploic vein is drained to both dural sinus and occipital vein; in our series corresponding IOF+EOF were found in $13.3 \%$ of the skulls. In (b) the occipital diploic vein drains only to the occipital vein through EOF (8\%). In (c) the draining of the occipital diploic vein is only toward dural sinuses through IOF (16\%). The short direct anastomosis in (d) is the OEV passing through OEF (1.3\%). ODV: occipital diploic vein; OEV: occipital emissary vein; OS: occipital sinus; OV: occipital vein; SS: straight sinus; SSS: superior sagittal sinus. 
described as an anastomosing venous channel along the occipital diploic vein. Any incomplete foramina on the midline of the inner or outer surfaces of the squamous part of occipital bone (Figures 3a-c) are most probably for the occipital diploic veins draining to the dural sinuses or extracranial occipital vein.

\section{Author Contributions}

All authors equally contributed.

\section{References}

1. Federative Committee of Anatomical Terminology (FCAT). Terminologia anatomica: international anatomical terminology. Stuttgart: Georg Thieme Verlag; 1998. p. 1-292.

2. Clemente CD (ed). Anatomy of the human body. 30th ed. Philadelphia: Lea and Febiger; 1985. p. 1-1676.

3. Williams PL, Bannister LH, Berry MM, Collins P, Dyson M, Dussek JE, Ferguson MWJ (eds). Gray's anatomy. 38th ed. Edinburgh: Churchill Livingstone; 1995. p. 1-2092.

4. Standring S (ed). Gray's anatomy: the anatomical basis of clinical practice. 41st ed. London: Elsevier; 2016. p. 1-1562.

5. Boyd GI. The emissary foramina of the cranium in man and the anthropoids. J Anat 1930;65:108-21.

6. Kadanoff D, Mutafov S. The human skull in a medico-anthropological aspect: form, dimensions and variability. Sofia: Prof. Marin Drinov Academic Publishing House; 1984. p. 121.

7. Sharma PK, Malhotra VK, Tewari SP. Emissary occipital foramen. Anat Anz 1986;162:297-8.

8. Premsagar IC, Lakhtakia PK, Bisaria KK. Occipital emissary foramen in Indian skulls. J Anat 1990;173:187-8.
9. Gözil R, Kadioglu D, Calgüner E. Occipital emissary foramen in skulls from Central Anatolia. Acta Anat (Basel) 1995;153:325-6.

10. Hossain SMA, Rahman L, Karim M. Occipital emissary foramen in Bangladeshi skulls. Pakistan Journal of Medical Sciences 2001;17: 156-8.

11. Louis RG Jr, Loukas M, Wartmann CT, Tubbs RS, Apaydin N, Gupta AA, Spentzouris G, Ysique JR. Clinical anatomy of the mastoid and occipital emissary veins in a large series. Surg Radiol Anat 2009;31:139-44.

12. Murlimanju BV, Prabhu LV, Pai MM, Jaffar M, Saralaya VV, Tonse M, Prameela MD. Occipital emissary foramina in human skulls: an anatomical investigation with reference to surgical anatomy of emissary veins. Turk Neurosurg 2011;21:36-8.

13. Singhal S, Ravindarath R. Occipital emissary foramina in South Indian modern human skulls. International Scholarly Research Notices (ISRN) Anatomy 2013;2013:1-4.

14. Cakmak PG, Ufuk F, Yagci AB, Sagtas E, Arslan M. Emissary veins prevalence and evaluation of the relationship between dural venous sinus anatomic variations with posterior fossa emissary veins: MR study. Radiol Med 2019;124:620-7.

15. Hedjoudje A, Piveteau A, Gonzalez-Campo C, Moghekar A, Gailloud P, San Millán D. The Occipital emissary vein: a possible marker for pseudotumor cerebri. Am J Neuroradiol 2019;40:973-8.

16. Mohsenipour I, Goldhahn W-E, Fischer J, Platzer W, Pomaroli A. Approaches in neurosurgery: central and peripheral nervous system. Stuttgart: Georg Thieme Verlag; 1994. p.107-25.

17. San Millán Ruíz D, Gailloud P, Rüfenacht DA, Delavelle J, Henry $\mathrm{F}$, Fasel JH. The craniocervical venous system in relation to cerebral venous drainage. Am J Neuroradiol 2002;23:1500-8.

18. Okudera T, Huang YP, Ohta T, Yokota A, Nakamura Y, Maehara F, Utsunomiya H, Uemura K, Fukasawa H. Development of posterior fossa dural sinuses, emissary veins, and jugular bulb: morphological and radiologic study. Am J Neuroradiol 1994;15:1871-83.
ORCID ID:

L. Jelev 0000-0001-8596-7867; L. Malinova 0000-0002-6928-1483
Correspondence to: Lazar Jelev, MD, PhD, Professor Department of Anatomy, Histology and Embryology, Medical University of Sofia, Sofia, Bulgaria Phone: +359-897-87-27-51 e-mail: ljelev@abv.bg Conflict of interest statement: No conflicts declared.

This is an open access article distributed under the terms of the Creative Commons Attribution-NonCommercial-NoDerivs 3.0 Unported (CC BY-NCND3.0) Licence (http://creativecommons.org/licenses/by-nc-nd/3.0/) which permits unrestricted noncommercial use, distribution, and reproduction in any medium, provided the original work is properly cited. Please cite this article as: Jelev L, Malinova L. Occipital emissary foramina in human skulls: review of literature and proposal of a classification scheme of the occipital venous anastomoses in the posterior cranial fossa. Anatomy 2020;14(1):11-15. 